20

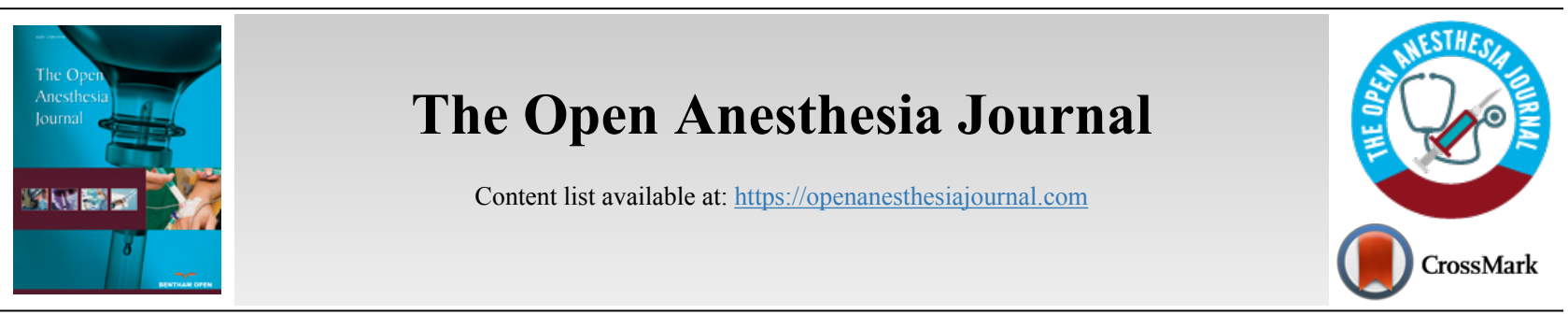

LETTER

\title{
If the Price is Right? Cost Analysis of Propofol Infusions and Sevoflurane Anaesthesia in Endoscopic Cases
}

\author{
Lachlan J. Gan ${ }^{1, *}$ and Gavin Sullivan ${ }^{1,2}$ \\ ${ }^{\prime}$ Department of Anaesthesia, Belmont District Hospital, Belmont NSW 2298, Australia \\ ${ }^{2}$ Department of Anaesthesia, John Hunter Hospital, New Lambton Heights NSW 2305, Australia
}

\begin{abstract}
:
The environmental superiority of Total Intravenous Anaesthesia (TIVA) compared to inhaled agents has been recognised by ANZCA in a 2019 statement. Yet what about cost? Little current data has been published on this topic. We conducted a cost analysis and audit of propofol use in 71 endoscopy cases (colonoscopy/gastroscopy), taking into account the cost of adjuncts (syringes, tubing, and discarded propofol). We then compared these to calculated costs of the same cases performed with sevoflurane anaesthesia. In terms of the agent, propofol was $35 \%$ cheaper, costing $\$ 1.60$ for an average endoscopy compared to a sevoflurane cost of $\$ 2.46$. Including the cost of adjuncts (including a laryngeal mask airway for sevoflurane anaesthesia), endoscopy cases with propofol infusions were $80 \%$ cheaper than the same case performed under sevoflurane general anaesthesia (\$3.08 vs \$15.48). Although pricing may vary from hospital to hospital, our data suggests choosing propofol costs less in endoscopy.
\end{abstract}

\begin{tabular}{|l|l|l|l|}
\hline Article History & Received: July 15, 2020 & Revised: November 15, 2020 & Accepted: December 09, 2020
\end{tabular}

The environmental superiority of Total Intravenous Anaesthesia (TIVA) compared to inhaled agents has been recognised by ANZCA in a 2019 statement [1]. Yet what about cost?

Little current data has been published on this topic. $55.5 \%$ of respondents to a 2018 survey by Lim et al. thought that TIVA was more expensive than inhaled anaesthesia [2]. A 2018 international survey by Wong et al. showed that cost was a barrier for $28 \%$ of infrequent TIVA users [3]. In response, Lam \& Ng published findings of a cost analysis from 2016. Contrary to previous publications, they showed that TIVA was in fact cheaper than low flow inhaled anaesthesia [4]. Their results provide a much-needed update on one factor influencing the choice of anaesthetic technique: cost. We wondered whether the findings were reproducible outside their centre.

In our institution, anaesthesia for endoscopy (colonoscopy and/or gastroscopy) is delivered through a propofol infusion targeting deep sedation (often requiring simple airway support), or through sevoflurane inhalation via a laryngeal mask airway with full general anaesthesia. To determine which choice was more economical, we conducted a 2020 cost analysis and audit of this population.

We audited 71 cases, taking into account the cost of syringes, extension tubing, and propofol (used and discarded).

\footnotetext{
* Address correspondence to this author at Department of Anaesthesia, Belmont District Hospital, Belmont NSW 2298, Australia 305;

E-mail: Lachlan.gan@health.nsw.gov.au
}

Drug and equipment pricing was obtained through the hospital ordering system and correspondence with the hospital pharmacy. We found that an average endoscopic case spent $\$ 1.59$ on propofol. Including adjuncts cost $\$ 3.08$ for 33 minutes of procedural time. An hour of propofol infusion cost $\$ 4.45$.

Figures were compared to calculated inhaled anaesthesia costs, based on Dion's formula and ideal fresh gas flows for induction and maintenance [5]. The cost of sevoflurane for 1 case was $\$ 2.46$. When Laryngeal Mask Airway (LMA) price was included, a typical endoscopy case maintained at 1 MAC cost $\$ 15.48$ at a fresh gas flow of $1 \mathrm{~L}$ - more than 5 times the infusion cost. $1 \mathrm{MAC}$-hour cost $\$ 16.64$ (Table. 1).

Our data would suggest that choosing propofol for endoscopy costs slightly less and saves $35 \%(\$ 0.86)$ per case. When costs of adjuncts are taken into account, the differences are far more significant - the same case done with inhaled anaesthesia costs over 5 times as much. On a typical list of 10 colonoscopy cases, this equates to saving $\$ 124$. Our study addresses a gap in the literature on the costs of infusion. We acknowledge its limitations as a single centre study with relatively modest sample size. There are also limitations as we have not captured data on any possible differences in different recovery times or staff workload. It also occurs occasionally that patients require LMAs during infusion cases for airway support. In this instance, the cost-benefit is minimized to $\$$ 1.32 . 
Table 1. Costs of propofol infusion and sevoflurane inhaled anaesthesia for an average endoscopy case and 1 hour.

\begin{tabular}{|c|c|c|c|c|}
\hline \multicolumn{5}{|c|}{ Cost (AUD) } \\
\hline- & $\begin{array}{c}33 \\
\text { Minutes* }\end{array}$ & $\begin{array}{c}\text { Adjuncts } \\
\text { Included** }\end{array}$ & 1 hour & $\begin{array}{c}\text { Adjuncts } \\
\text { Included }\end{array}$ \\
\hline $\begin{array}{c}\text { Propofol } \\
\text { Infusion*** }\end{array}$ & 1.60 & 3.08 & 2.88 & 4.45 \\
\hline $\begin{array}{c}\text { Sevoflurane (2\% } \\
\text { at 1L FGF)**** }\end{array}$ & 2.46 & 15.48 & 3.62 & 16.64 \\
\hline
\end{tabular}

$* 33.38$ minutes $=$ average case length in the audit.

**Adjuncts $=$ extension tubing, syringes for TIVA. Laryngeal mask airway for inhaled anaesthesia $=\$ 12.35$.

$* * *$ Average volume $/$ case propofol used $=29.7 \mathrm{ml}$ (average discard volume $=12$ $\mathrm{ml})$. Propofol cost $\$ 0.0335 / \mathrm{ml} \mid \$ 0.042 / \mathrm{ml}$ for $20 \mathrm{ml} \mid 50 \mathrm{ml}$ vials respectively.

$* * * *$ Sevoflurane cost $\$ 0.4 / \mathrm{ml} .200 \mathrm{mg}$ propofol induction included in the cost of adjunct. $\mathrm{FGF}=$ fresh gas flow.

It is reasonable to expect small differences in costs across centres based on variations in pricing, and not all centres use propofol infusions for endoscopy. However, our study supports the notion that propofol infusions are not just environmentally friendly but also the cost-effective choice in endoscopy.

\section{CONSENT FOR PUBLICATION}

Not applicable.

\section{FUNDING}

None.

\section{CONFLICT OF INTEREST}

The authors declare no conflict of interest, financial or otherwise.

\section{ACKNOWLEDGEMENTS}

Declared none.

\section{REFERENCES}

[1] Australian and New Zealand College of Anaesthetists (ANZCA) Statement on environmental sustainability in anaesthesia and pain medicine practice (PS64BP) Australian and New Zealand College of Anaesthetists, July 2019. Melbourne, Victoria: ANZCA 2019.

[2] Lim A, Braat S, Hiller J, Riedel B. Inhalational versus propofol-based total intravenous anaesthesia: Practice patterns and perspectives among Australasian anaesthetists. Anaesth Intensive Care 2018; 46(5): 480-7.

[http://dx.doi.org/10.1177/0310057X1804600509] [PMID: 30189822]

[3] Wong GTC, Choi SW, Tran DH, Kulkarni H, Irwin MG. An international survey evaluating factors influencing the use of total intravenous anaesthesia. Anaesth Intensive Care 2018; 46(3): 332-8. [http://dx.doi.org/10.1177/0310057X1804600312] [PMID: 29716493]

[4] Lam DH, Ng MD. A cost comparison between total intravenous and volatile-based anaesthesia. Anaesth Intensive Care 2018; 46(6): 633. [PMID: 30447680]

[5] Mapleson WW. The theoretical ideal fresh-gas flow sequence at the start of low-flow anaesthesia. Anaesthesia 1998; 53(3): 264-72. [http://dx.doi.org/10.1046/j.1365-2044.1998.00310.x] [PMID: 9613272]

(C) 2021 Gan \& Sullivan.

This is an open access article distributed under the terms of the Creative Commons Attribution 4.0 International Public License (CC-BY 4.0), a copy of which is available at: https://creativecommons.org/licenses/by/4.0/legalcode. This license permits unrestricted use, distribution, and reproduction in any medium, provided the original author and source are credited. 